\title{
Can Curious Employees be More Innovative? Exploring the Mechanism of Intrinsic Motivation and Job Autonomy
}

\author{
Qiuling Huang \\ School of Management, Jinan University, Guangzhou, China \\ Email: melodyhuang1128@126.com
}

How to cite this paper: Huang, Q. L. (2021). Can Curious Employees be More Innovative? Exploring the Mechanism of Intrinsic Motivation and Job Autonomy. Psychology, 12, 425-440.

https://doi.org/10.4236/psych.2021.123027

Received: February 24, 2021

Accepted: March 28, 2021

Published: March 31, 2021

Copyright $\odot 2021$ by author(s) and Scientific Research Publishing Inc. This work is licensed under the Creative Commons Attribution International License (CC BY 4.0).

http://creativecommons.org/licenses/by/4.0/

\begin{abstract}
Innovation enables organizations to survive and maintain sustainability in today's increasingly competitive business environment. Employee innovation is an issue that has received much attention from enterprises and academic circles and has never been out of date. Curiosity is the beginning of the desire for knowledge, has always been regarded as the source of instructions for innovation. However, the idea that curiosity promotes innovation is not supported by empirical research. Here, we broaden our understanding of curiosity in an organizational context through an empirical investigation how work curiosity influences innovation behavior. We also propose that the mediating role of intrinsic motivation and the moderating role of job autonomy in the abovementioned relationships. Through two-stage paired tracking and multi-source questionnaire survey, using SPSS22.0 and Mplus7.0, and based on data collected from 247 participants in China, we tested our hypotheses concerning these relationships. The study has implications for enterprises to promote employee innovation, especially through "micro-innovation" to promote "big innovation".
\end{abstract}

\section{Keywords}

Work Curiosity, Innovation Behavior, Intrinsic Motivation, Job Autonomy, Trait Activation

\section{Introduction}

For contemporary VUCA environments, the competition among industries is becoming increasingly fierce (Horstmeyer, 2020). If organizations want to survive in the current difficult business environment and maintain a steady stream 
of endurance, it is no longer enough to hold the attitude of doing things in the past. Only continuous innovation can cope with the challenges and unexpected changes that come at any time (Yuan \& Woodman, 2010). Employees are the most indispensable part of an enterprise's innovation process. Under the guidance of China's "mass entrepreneurship and innovation" policy, employee innovation behavior is particularly important for the effectiveness and survival of an organization. It can not only guide the sustainable development of an organization, but also serve as the driving force of China's economic supply-side reform. How to stimulate employee innovation is a problem that has never been out of date. Innovation in the current Internet context is facing new challenges. The information explosion brought by the mobile Internet era, as a result, people's ability to think deeply is being eroded by fragmented information. $\mathrm{Cu}$ riosity is the beginning of the desire for knowledge, curious individuals have a strong desire to learn, are able to solve difficult problems, ask tough questions, and are never satisfied with just getting things done. In the Internet era with the expansion of information, it is necessary to cultivate and maintain employees' curiosity, that is, the continuous demand for learning, exploration and discovery, keep employees thinking actively and thinking deeply is an important good way to deal with the challenges faced by employee innovation in the context of the Internet.

Since the concept of "work curiosity" was put forward (Mussel, 2013), empirical results also show that work curiosity can bring motivational, cognitive and behavioral contributions to employees, For example, curiosity-induced information-seeking behaviors, such as information-seeking behaviors, promote employees' learning in the workplace, help employees quickly adapt to the new environment, improve job performance and experience more psychological well-being and less emotional exhaustion (Harrison et al., 2011; Mussel \& Spengler, 2015; Reio \& Callahan, 2004; Wang \& Li, 2015). Business leaders recognize a strong relationship between curiosity and innovation, and regard curiosity as a mechanism to promote success (Gino, 2018). However, at present, the empirical research evidence that the positive trait of curiosity is the distal influencing factor of innovative behavior is still weak, more research is needed to determine how the two structures are related (Gross et al., 2020). Therefore, the first purpose of this study is to focus on the positive predictive effect of employees' work curiosity on innovation behavior in Chinese context. The second question considered in this study is how does curiosity as an individual trait translate into the behavioral outcomes expected by the organization. Specifically, this study proposes intrinsic motivation as a mediator of work curiosity influence innovation. Employees with high curiosity are interested in and excited about the acquisition of creative problem-solving information (Litman, 2005). Curiosity creates the desire and interest in exploration activities, resulting in individuals seeking new information and exploring behavior independently (Litman et al., 2005). According to trait activation theory, the process of individual trait activation is conducive to meet internal or external work motivation, thus showing valuable 
work behavior (Tett et al., 2013). The motivation perspective model of creativity also suggests that traits positively related to creativity are usually associated with intrinsic motivation (van Knippenberg \& Hirst, 2020). Although curious employees are empirically better at exploring and asking questions, but in the workplace, employees often feel that their curiosity doesn't have free rein. A large cross-cultural sample study results show that 60 percent of 3000 employees believe that curiosity is essential, but the same proportion of employees say that curiosity is hindered at work (Chang \& Shih, 2019), which indicates that the performance of employees' curiosity is influenced by situational factors, Ishaq et al. (2019) also appeal in the study that needs to explore the boundary conditions of work curiosity in future study. According to trait activation theory, personality traits can effectively predict behavior only when the situation provides clues or opportunities for the behavioral expression of personality traits. Therefore, we final introduce job autonomy as the boundary condition that work curiosity affects employees' innovative behavior through intrinsic motivation.

\section{Theory and Hypotheses}

\subsection{Work Curiosity and Innovation Behavior}

According to trait activation theory, individual traits can directly influence personality related behavioral tendencies (Tett \& Burnett, 2003). Innate curiosity, as a personality trait, is often associated with the search for unknown and novel information, curious individuals have a natural desire to recognize, pursue, and explore new things, challenges, and uncertainties. Curiosity is an important psychological characteristic that human beings need to have when carrying out exploratory and creative activities (Litman et al., 2005), can inspire people to learn and immerse themselves in information they are interested in, expand information, knowledge and skills by focusing on novelty and challenges, and think, explore and act in new ways. Amabile et al. (1996) also pointed out that people who make great achievements are not those with talents but those individuals full of strong curiosity, curiosity is the main driving force of innovation in organization. It is found that there is a significant positive correlation between trait curiosity and individual creative self-efficacy and creative self-identity (Karwowski, 2012). Research also found that specific curiosity was able to predict the next day's job creativity, among which idea linking played a mediating role (Hagtvedt et al., 2019). According to trait activation theory, employees with high curiosity traits are a group of individuals with high creative potential. When curiosity is aroused, employees will consciously recognize and seek for information and experience beyond what is required by the job and immerse themselves in it; awareness of a lack of knowledge or ability to deal with complex problems and motivate them to explore unsolved problems or problems; openness to other people's ideas, which helps them better identify problems; and be open to the anxiety of new things, unfamiliarity and uncertainty, the above performance will lead employees to feel enthusiastic and energetic psychologically, 
expand their thinking, confident and optimistic emotionally, as well as the sharing and integration of knowledge, experience and information, which is conducive to the generation of employees' innovative behaviors. Based on the above theoretical analysis and deduction, this paper has reached the following hypothesis:

H1: Work curiosity has a positive effect on employees' innovation behavior.

\subsection{Work Curiosity and Intrinsic Motivation}

Curiosity can motivate individuals to seek out missing information to close the information gap or seek out new information to reduce boredom, like hunger, thirst, and sexual desire, the process of curiosity is a process of seeking knowledge and information to achieve satisfaction (Litman, 2007). High desire is the salient feature of curiosity. The desire for knowledge drives people to explore and acquire the deprived information, thus completing the need for cognitive closure (Loewenstein, 1994). The dynamic nature of curiosity means that satisfying curiosity is like an internal reward that can enhance people's exploration and learning (Wang \& Huang, 2018). From the perspective of information reward of curiosity, the process of curiosity satisfaction itself is an internal self-reward process (Loewenstein, 1994), obtaining missing information is the reward goal pursued by individuals. Therefore, individuals will take the initiative to explore in order to obtain the reward target (the information they want to know) and obtain the knowledge information they want to know or the novel information they don't need (Litman, 2005). The greater the degree of curiosity, the stronger the individual's willingness to explore (Litman, 2008; Litman \& Jimerson, 2004), and regards the process of exploring until the goal is achieved as an intrinsic reward, without considering other benefits. Intrinsic motivation is the internal driving force of individual behavior. It emphasizes that the main objective of individuals engaged in work is to pursue work pleasure, spontaneous satisfaction, sense of competence, curiosity and challenge, rather than to obtain material rewards. Employees with trait work curiosity will actively seek the pleasure brought by acquiring new knowledge and experience and the sense of ability brought by reducing ambiguity in work, increasing the sense of pleasure and ability encourages employees to show more intrinsic drive to explore, and encourages individuals to find intrinsic rewards in the process of exploration, thinking and active learning. In the process of curiosity stimulation, it is manifested as the individual's external seeking action, and the internal performance is the enhancement of the individual's intrinsic motivation. The above analysis has enabled the following hypothesis:

$\mathrm{H} 2$ : Work curiosity has a positive effect on intrinsic motivation.

\subsection{The Mediation Effect of Intrinsic Motivation}

The level of curiosity can cause the intrinsic motivation to respond accordingly, because when the curiosity trait is activated, it is followed by the drive and desire to explore, thus strengthening the internal motivation of the individual (Lauriola 
et al., 2015). Moreover, driven by intrinsic motivation, employees consciously devote themselves to work, explore and dig new ideas and ideas more actively, and promote the generation of innovative behaviors (Fischer et al., 2019). First of all, the intrinsic motivation is the internal and continuous action force that employees have out of interest in the work itself. At the same time, this visceral desire to work spurs employees to come up with creative ideas. In this process, employees also enjoy the pleasure of the innovation process. Moreover, strong intrinsic motivation can stimulate flexibility. It enables employees to deal with more challenging tasks flexibly, not to be afraid of pressure, stimulate their enthusiasm for innovation, and actively seek efficient solutions, which is more conducive to the generation of innovative behaviors of employees. As a result, work curiosity not only directly acts on innovative behavior, but also indirectly acts on innovative behavior through intrinsic motivation. According to the trait activation theory, in the whole process of trait activation, individuals will get an intrinsic satisfaction generated in the process of trait activation, so as to display good work behavior. Therefore, this has led to the third hypothesis in this paper:

H3: Intrinsic motivation mediates the relationship between work curiosity and innovation behavior.

\subsection{Moderating Effect of Job Autonomy}

Trait activation theory points out that the predictive power of individual trait on individual behavior is affected by situational factors related to the trait, and the transformation of individual trait into work behavior is in response to situational cues related to the trait (Tett \& Guterman, 2000). Trait-related cues in the context will stimulate the individual's personality traits, and when the individual's situation matches its personality traits, the relationship between the trait and the individual's behavior will be enhanced, otherwise, it will be weakened. In considering trait activation, contextual cues associated with it should be considered. Job characteristics are probably one of the important situational cues. Job autonomy refers to the degree to which an individual can determine his or her method, speed, and effort to complete a task (Hackman, 1980; Spector, 1986). In cases where individuals have a high degree of autonomy in their work, behavior is more likely to be related to individual personality differences because there is discretion in the choice of behavior to complete a given task or achieve a given goal. However, under the condition of low work autonomy, individual behavior may be restricted by a variety of factors, including close supervision, machine-driven pace and detailed work rules. Therefore, in the case of low job autonomy, personality may play little or no role in individual behavior, because individuals have no judgment on performance-related activities. In the case of high job autonomy, it is acceptable, even desirable, to change the way you work (for example, lack of supervision, limited task structure, no external pace signals, colleague communication). Employees with work curiosity may respond to these clues, and encourage employees to explore the environment and obtain new in- 
formation to satisfy the inner drive of curiosity. In situations where work autonomy is low, there is little evidence that individual initiative exploration is acceptable or desirable, external situational factors limit employees' intrinsic drive to explore according to their own curiosity and subsequent exploration behavior. From the perspective of trait activation, high job autonomy can "activate" work curiosity, while low job autonomy may have low trait activation potential. We, therefore, hypothesize that job autonomy moderates the relationship between work curiosity and intrinsic motivation, such that the positive relationship is strongest when job autonomy is high.

H4: Job autonomy positively moderates the relationship between work curiosity and intrinsic motivation.

As a result, this study has developed the following hypothesis, with a conceptual model shown in Figure 1.

\section{Research Method}

\subsection{Sampling}

Data we collected from different organizations, including IT, manufacturing, internet, financial. A total of 350 questionnaires were distributed. Participants were recruited through the author' personal and professional contacts. We sent emails with instructions and questionnaires to participants, in the email, we explained the scope of the study, assured the confidentiality of participants' responses and clarified that participation was voluntary. To avoid common method variance (CMV), data were collected at two measurement points: Time 1 (independent variable and moderator) and Time 2 (mediator and dependent variable). A total of 266 questionnaires were returned, which corresponds to a $76 \%$ response rate. After excluding questionnaires with incomplete data, 247 questionnaires were used for analysis; hence, the final response rate was $70.0 \%$.

Of the 247 respondents, $46.6 \%$ were male. Most of the respondents were between 26 and 35 years old (68.83\%). Most participants had an undergraduate university degree (87.67\%) and some had a master's degree (13.0\%). Most of the participants worked in manufacturing (29.1\%), internet (15.0\%), IT (10.9\%), and the construction (10.1\%).6.1\% respondents had less than 1 year of work experience; $46.2 \%$ had 1 - 5 years of work experience.

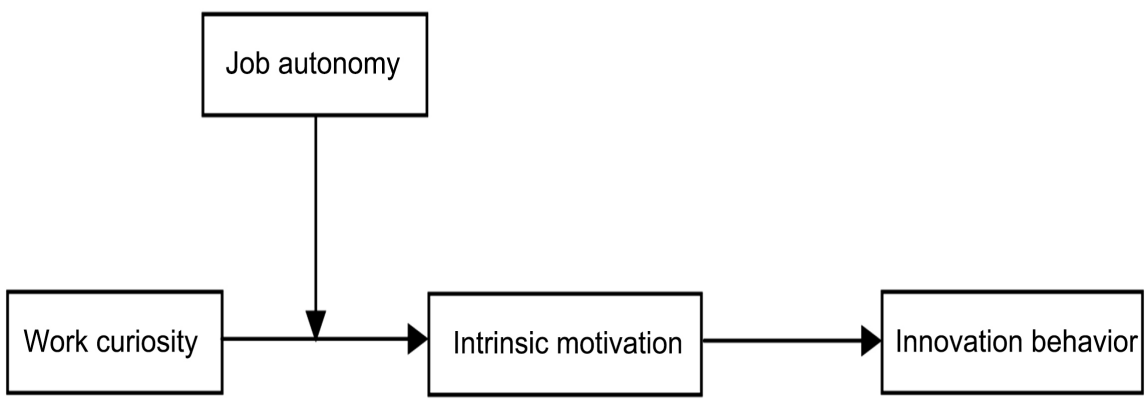

Figure 1. Research model. 


\subsection{Measures}

To test the proposed hypotheses, multi-item scales from prior literature were used for the measurement of the constructs; most of the items were measured by using a 5-point Likert scale ranging from 1 (strongly disagree) to 5 (strongly agree).

Work curiosity (WC) was assessed using the 16 items multidimensional workplace trait curiosity scale developed by Kashdan et al. (2020). The scale consists of four dimensions: openness to people's ideas, stress tolerance, deprivation sensitivity, and joyous exploration. Sample items include "At work, I seek out opportunities to expand my knowledge or skills" and "I can spend hours on a single problem because of a need to find an answer".

Intrinsic motivation (IM) was evaluated with 6 items scale from Amabile et al. (1994). The respondents were asked to rate the extent to which they did their work for its own sake, because it was enjoyable to them. A sample item is "What matters most to me is enjoying what I do".

Job autonomy (JA) was measured using the 7-item scale adapted by Kirmeyer and Shirom (1986) by asking the participants to indicate the extent to which they agreed with the statement about the freedom they feel regarding to their work, such as when they work, with whom they work, how they finish their work, and so on. Sample item: "To what extent do you feel you have latitude to decide when to take breaks".

For innovative behavior (IB), participants completed the 5-item Innovative Behavior Scale (Liu \& Shi, 2009) to rate the extent to which, at work, they exhibited behaviors involving innovation (e.g., this month, at work I promoted and championed ideas to others).

Control variables. Apart from those, two demographic and two additional control variables were measured in this study. Previous studies have indicated that factors such as gender, age, education background, and experience in the start-up related to IB. Therefore, control on the factors mentioned above has been strictly followed while selecting participants.

\section{Analysis and Results}

\subsection{Measure Validity and Reliability}

The reliability and validity of the variables were assessed after data collection through confirmatory factor analysis (Fornell \& Larcker, 1981). Table 1 presents the fit statistics for all models. The four-factor model fit the data better than any of the alternatives. The results show that the model fits adequately: $\mathrm{CFI}=0.853$, $\mathrm{TLI}=0.840, \chi^{2} / \mathrm{df}=1.58, \mathrm{RMSEA}=0.047$ and $\mathrm{SRMR}=0.065$.

\subsection{Common Method Variance Assessment}

Since all measurement scales were self-reported, there would be a potential for common method variance (CMV) caused by multiple reasons such as social desirability and consistency motif. Thus, we conducted Harman's single factor 
Table 1. CFA with alternative models $(\mathrm{N}=247)$.

\begin{tabular}{ccccccc}
\hline Model & Description & $\chi / \mathrm{df}$ & CFI & TLI & RMSEA & SRMR \\
\hline One-factor model & All variables combined & $1226.04 / 527$ & 0.661 & 0.639 & 0.071 & 0.078 \\
Two -factor model & WC, IM + IB + JA & $1046.31 / 522$ & 0.746 & 0.727 & 0.061 & 0.074 \\
Three -factor model & WC, IM + IB, JA & $860.36 / 520$ & 0.835 & 0.822 & 0.050 & 0.067 \\
Four-factor model & WC, IM, JA, IB & $821.08 / 517$ & 0.853 & 0.840 & 0.047 & 0.065 \\
\hline
\end{tabular}

Note: WC: work curiosity; IM: intrinsic motivation; IB: innovative behavior; JA: job autonomy.

test to address CMV (Podsakoff et al., 2003). This test suggests that CMV is present if the majority of variance is explained by a single factor, or if a single factor emerges from the exploratory factor analysis (EFA) of all variables. An EFA was conducted on all variables, with the number of factors constrained to one. An unrotated factor solution was conducted, as well as an EFA based on eigen values greater than 1 . The unrotated factor solution identified four factors with a cumulative variance of $81.68 \%$, in which the largest factor explained $23.49 \%$ of variance. This confirms that a single factor is not sufficient to explain the majority of the variance; therefore, CMV is not serious.

\subsection{Descriptive Statistics}

Table 2 presents the means, standard deviations and Pearson's correlations for all study variables. All correlations were in the expected direction. We found that work curiosity was also significantly correlated with innovative behavior $(\mathrm{r}=$ $0.52, p<0.01)$ and intrinsic motivation $(\mathrm{r}=0.43, p<0.01)$. Finally, intrinsic motivation was significantly correlated with innovative behavior $(\mathrm{r}=0.42, p<0.01)$.

\subsection{Hypothesis Testing}

This study has applied hierarchical regression analysis to test the research hypothesis with SPSS 22.0 software, by firstly verifying whether work curiosity would positively affect innovative behavior when innovation behavior was set as the dependent variable. With control of gender, age, education background, and experience in the start-up (Model 1 of Table 3), work curiosity continued to be added to Model 2. The results demonstrated that H1 was supported with a reported significant association between work curiosity and innovative behavior in Model $2(\beta=0.504, p<0.001)$.

Secondly, intrinsic motivation was also set as a dependent variable to check whether it was positively affected by work curiosity. On the basis of controlling variables, Model 6 has suggested that work curiosity has a significantly positive effect on intrinsic motivation ( $\beta=0.424, p<0.001$ ), thus to support $\mathrm{H} 2$.

Thirdly, the mediating effect of intrinsic motivation between work curiosity and innovative behavior has been tested by judging whether the following three conditions were met. That is, 1) work curiosity significantly correlates with innovative behavior; 2) work curiosity significantly relates to intrinsic motivation; 
Table 2. Descriptive statistics and correlations among the variables $(\mathrm{N}=247)$.

\begin{tabular}{|c|c|c|c|c|c|c|c|c|c|c|}
\hline Variables & Mean & $\mathrm{SD}$ & 1 & 2 & 3 & 4 & 5 & 6 & 7 & 8 \\
\hline 1) Gender & 1.53 & 0.50 & & & & & & & & \\
\hline 2) Age & 2.09 & 0.57 & -0.02 & & & & & & & \\
\hline 3) Education background & 2.97 & 0.62 & $-0.16^{* *}$ & 0.01 & & & & & & \\
\hline 4) Experience in the start-up & 4.07 & 1.02 & $0.16^{*}$ & $-0.12^{*}$ & $0.46^{* *}$ & & & & & \\
\hline 5) Job type & 3.15 & 1.69 & $0.20^{* *}$ & 0.02 & -0.10 & $-0.14^{\star}$ & & & & \\
\hline 6) Work curiosity & 3.84 & 0.49 & -0.01 & -0.04 & 0.02 & 0.10 & $-0.17^{\star *}$ & & & \\
\hline 7) Intrinsic motivation & 4.06 & 0.46 & 0.03 & 0.01 & -0.08 & 0.04 & -0.03 & $0.43^{* *}$ & & \\
\hline 8) Innovation behavior & 3.43 & 0.67 & -0.08 & 0.11 & 0.06 & $0.18^{* *}$ & $-0.13^{\star \star}$ & $0.52^{\star *}$ & $0.42^{\star *}$ & \\
\hline 9) Job autonomy & 3.84 & 0.66 & 0.05 & 0.05 & 0.05 & $0.16^{*}$ & 0.01 & $0.36^{* *}$ & $0.22^{* *}$ & $0.33^{* *}$ \\
\hline
\end{tabular}

Note: $\mathrm{N}=247 .{ }^{\star}$ Correlation is significant at the level of 0.05 (two-tailed). ${ }^{* *}$ Correlation is significant at the level of 0.01 (two-tailed).

Table 3. Regression analysis of hypotheses $(\mathrm{N}=247)$.

\begin{tabular}{|c|c|c|c|c|c|c|c|c|}
\hline \multirow{2}{*}{ Variables } & \multicolumn{4}{|c|}{ Innovation behavior } & \multicolumn{4}{|c|}{ Intrinsic motivation } \\
\hline & Model1 & Model 2 & Model 3 & Model 4 & Model5 & Model 6 & Model 7 & Mode8 \\
\hline 1) Gender & -0.040 & -0.037 & -0.051 & -0.044 & 0.028 & 0.030 & 0.025 & 0.020 \\
\hline 2) Age & 0.094 & 0.122 & 0.086 & 0.112 & 0.021 & 0.044 & 0.042 & 0.034 \\
\hline 3) Education background & 0.053 & 0.043 & 0.089 & 0.066 & -0.089 & -0.097 & -0.101 & -0.105 \\
\hline 4) Experience in the start-up & $0.152^{\star}$ & 0.104 & 0.127 & 0.099 & 0.062 & 0.022 & 0.012 & -0.009 \\
\hline 5) Job type & -0.019 & -0.031 & -0.083 & -0.032 & -0.055 & 0.008 & -0.002 & -0.011 \\
\hline 6) Work curiosity (WC) & & $0.504^{* * *}$ & & $0.404^{* * *}$ & & $0.424^{* * *}$ & $0.393^{\star * *}$ & $0.446^{* * *}$ \\
\hline 7) Intrinsic motivation & & & $0.403^{* * *}$ & $0.236^{* * *}$ & & & & \\
\hline 8) Job autonomy (JA) & & & & & & & 0.089 & 0.101 \\
\hline 9) $\mathrm{WC} \times \mathrm{JA}$ & & & & & & & & $0.186^{* *}$ \\
\hline $\mathrm{R}^{2}$ & 0.070 & 0.313 & 0.229 & 0.358 & 0.016 & 0.188 & 0.195 & 0.226 \\
\hline Adjusted $\mathrm{R}^{2}$ & 0.044 & 0.290 & 0.204 & 0.334 & -0.011 & 0.162 & 0.165 & 0.193 \\
\hline F & 2.678 & 13.85 & 9.056 & 14.786 & 0.589 & 7.508 & 6.419 & 6.837 \\
\hline
\end{tabular}

Note: $\mathrm{N}=247,{ }^{* * *} \mathrm{p}<0.001,{ }^{* *} \mathrm{p}<0.01,{ }^{*} \mathrm{p}<0.05$.

and 3) when intrinsic motivation is included in the relation between work curiosity and innovative behavior, it is a complete mediation if the relation between work curiosity and innovative behavior is not significant while that between intrinsic motivation and innovative behavior is. Otherwise, intrinsic motivation plays a partial mediating role, if there still exists the correlation between work curiosity and innovative behavior; however, the correlation coefficient decreases. This study has verified the significant effect of work curiosity on inno- 
vative behavior and intrinsic motivation respectively in Model 2 and Model 6. Model 3 has revealed that both work curiosity and intrinsic motivation influence innovative behavior to a great extent $(\beta=0.404, p<0.001 ; \beta=0.236, p<0.001)$, and the coefficient correlation is less than 0.504 (Model 2) when intrinsic motivation is included. Consequently, intrinsic motivation plays a partial mediating role in the correlation between work curiosity and innovative behavior, thus supporting $\mathrm{H} 3$.

We finally conducted regression analysis to test the hypothesis that the association between work curiosity and innovative behavior would be strengthened by job autonomy. This study followed the moderated regression procedures recommended by Aiken et al. (1991). Independent variables and job autonomy were mean-centered ahead of analysis to reduce potential multi-collinearity problems. Meanwhile, we constructed the interaction of work curiosity and job autonomy (WC $\times \mathrm{JA})$ and thus suggested the existence of the moderating effect when the coefficient of interaction was significant (Aiken et al., 1991). As shown in Models 5 - 8 in Table 3, we entered the control variables in Model 5, work curiosity in Model 6, job autonomy in Model 7, and the interaction in Model 8. In addition to the core hypothesis of the relationship between work curiosity and intrinsic motivation. As predicted in Hypothesis 4, Model 8 identified that the interaction coefficient is significant $(\beta=0.186, p<0.01)$, suggesting that job autonomy acts as a moderating role between work curiosity and intrinsic motivation. Simple slope tests were also conducted to further verify the interpretation of the interaction. Figure 2 was plotted for the relationship between work curiosity and intrinsic motivation at one standard deviation above and below the mean of job autonomy. As expected, for individuals with a high sense of job autonomy (one standard deviation above the mean), work curiosity significantly predicted a higher level of intrinsic motivation $(\mathrm{t}=2.583, p<0.05)$.

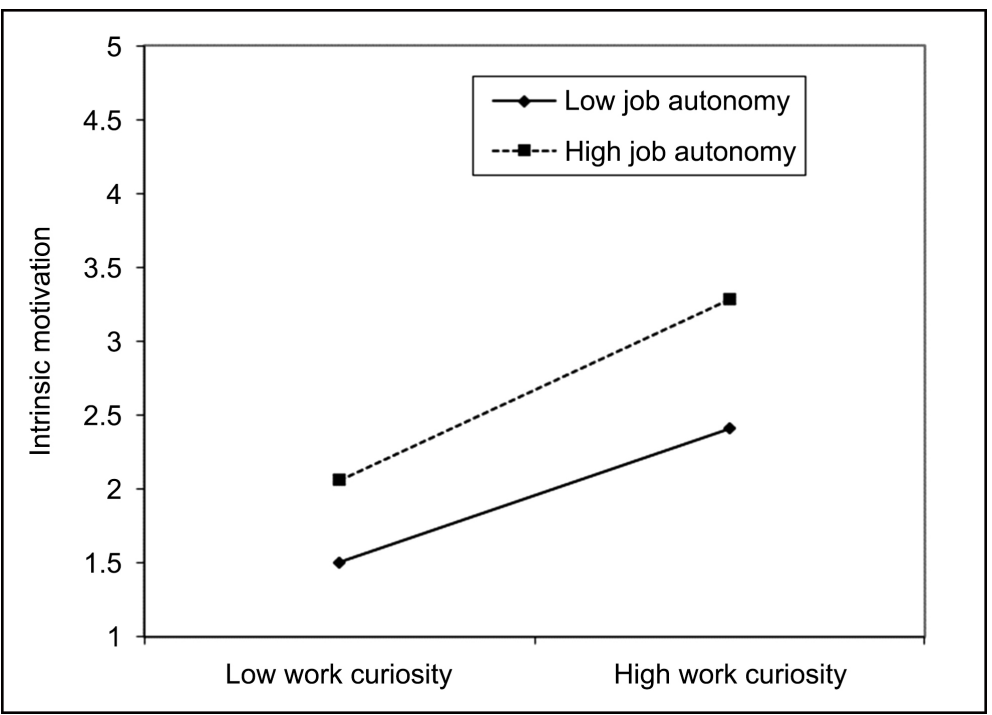

Figure 2. Moderating role of job autonomy in the relationship between work curiosity and intrinsic motivation $(\mathrm{N}=247)$. 


\section{Discussion}

Based on the trait activation theory, this study explores the internal mechanism and boundary conditions of how job curiosity influences employees' innovative behavior. First, this study has contributed theoretically by taking a close look at the process of work curiosity influencing innovative behavior, it is one of the few empirical studies to examine the effect of work curiosity on innovative behavior so far. From the perspective of an employee's characteristics, we developed how the innovative behavior of employees is affected by work curiosity and emphasized the significance of employees' psychological quality based on the empirical evidence from China. Kashdan et al. (2020) proposed that curious employees have four characteristics: joyous exploration, deprivation sensitivity, openness to people's ideas, and stress tolerance. Joyous exploration means that individuals actively seek new information when they do not lack the information needed to solve the problem, and in this process, they get a sense of pleasure for learning and growth; deprivation sensitivity means that employees seek the information they need to solve complex work-related problems until the problem is solved, Because of the epistemic nature of curiosity, employees with high curiosity will seek more novel information, Hardy III et al. (2017) found that curiosity affects information-seeking behavior, and when employees are more curious about their work, it encourages employees to participate in the process of seeking new information and knowledge, which helps them to identify work-related problems. Innovation begins with problem identification, and problem identification and information search are the first steps of innovation, a process of constantly gathering information that leads to the generation of creative ideas (Mumford \& McIntosh, 2017). Openness to people's ideas means to be open to the ideas of others, that is, to value the different views and ideas of others, to be willing to accept a variety of experiences, to look for different approaches to work, and to pay attention to the surrounding environment. Because employees attach importance to the suggestions of others, it is easier to find a connection between themselves and the ideas of others, promote the sharing and integration of knowledge, experience and information, and get useful suggestions and feedback from superiors or colleagues, thus stimulate innovative ideas and the knowledge or information needed to implement innovative ideas. In addition, stress tolerance enables employees to accept the anxiety and discomfort caused by new things, unfamiliarity and uncertainty, and explore unknown areas with confidence and clear purpose. Innovative activities are characterized by uncertainty, stress tolerance enables employees to improve their ability to cope with emergencies and withstand pressure in an uncertain environment, and actively deal with threats and challenges, which is conducive to the development of innovative behavior.

Secondly, our study also contributes to both work curiosity and innovative behavior literatures by demonstrating the work curiosity is beneficial to employee innovation through the mechanism of enhancing employees' intrinsic 
motivation. In the context of SDT, curiosity is often associated with intrinsic motivation (Deci \& Ryan, 1985), Curiosity causes an individual's internal desire to learn new information or acquire missing information. Acquiring knowledge out of curiosity is considered an inherent reward and a high degree of happiness because it eliminates ignorance and uncertainty or reduces boredom (Litman, 2005). As a driving force of behavior, intrinsic motivation is an activity for internal satisfaction rather than for some separable result, emphasizing self-determining goals and self-regulating behavior. Previous studies have also shown that curiosity is positively correlated with intrinsic motivation (Lauriola et al., 2015). Intrinsic motivation has always been regarded as an important factor affecting individual creativity. Employees with higher intrinsic motivation are more likely to have a strong desire for work and a stronger willingness to learn and explore. Intrinsic motivation to promote the employees to use professional knowledge to improve the ability of creative thinking, and invest more time and energy to solve difficult problems, show a strong willpower and persistence, and spontaneously explore the solution to solve the problem, which makes them more inclined to look for a variety of solutions to the problem, so that the employees showed high levels of creativity (Ryan \& Deci, 2000).

Moreover, this paper adds to the understanding of job autonomy as a situational characteristic that influence the play of curiosity by examining its moderating role in the relationship between work curiosity and intrinsic motivation. As an important dimension of work design, job autonomy positive moderates the relationship between work curiosity and intrinsic motivation. Compared with low job autonomy, at a high level of work autonomy, work curiosity has a stronger positive impact on intrinsic motivation. This may be because situations with low work autonomy leave room for employees' curiosity, even if curious employees are better at inquiring and asking questions, it takes time, energy and resources to be curious, and even in the workplace, employees often feel that their curiosity doesn't have room for free play. According to a two-year survey conducted by Merck on more than 3000 employees in 16 industries in China, the United States and Germany, 60 percent of employees believe that curiosity is essential, but the same proportion of employees say that curiosity is hindered at work (Chang \& Shih, 2019). If organizations set aside free-thinking space for employees' curiosity, create freedom in the workplace, encourage exploration and build trust, and allow employees to act according to their own curiosity, they can enhance their employees' intrinsic motivation, thus opening the way to innovation.

\section{Managerial Implications}

Curiosity does not necessarily kill the cat, curiosity can also make the cat more creative (Hagtvedt et al., 2019). The results of this study will help to increase the existing literature on work-related curiosity and provide management insights and practical significance for companies that want to make full use of their em- 
ployees' inherent curiosity and turn it into valuable organizational resources. In innovation practice, enterprises can encourage employees' curiosity, drive individual micro-innovation behavior, provide the basis for the development of organizational innovation and achieve great innovation. To cultivate employees' curiosity, enterprise organizations can start from the following aspects.

First, for jobs requiring innovation and strong uncertainty, such as in knowledge-intensive organizations, the trait of curiosity should be regarded as an important criterion in the employees' recruitment process (Müceldili et al., 2020). Second, build intellectual curiosity. Leaders should lead by example and demonstrate greater curiosity, which in turn drives greater curiosity throughout the organization. If the supervisor doesn't know the answer, admit it. This means they value the process of finding answers and motivate other employees to ask questions. Third, allow employees to explore and expand their interests, and create free time for employees to explore the problems they are curious about, instead of simply setting performance goals for employees. For example, $3 \mathrm{M}$ and Facebook provide their employees with free time to research novel and creative ideas (Gino, 2018). Finally, create a culture of curiosity, build a learning organization. There is an implicit message in many organizations: asking questions is a pointless challenge to authority. Both supervisors and employees focus on the job at hand without thinking about the details of the process or the overall goal. To stimulate and retain employee curiosity, organizations need to create an environment and culture that supports curiosity.

In short, curiosity can be cultivated, even for those who have lost their curiosity over time. Therefore, under the influence of the current COVID-19 epidemic, leaders should look at the development of enterprises from a long-term perspective (Wagstaff et al., 2020). It will be a valuable asset for employees and enterprises to make some appropriate investments to support and cultivate their curiosity.

\section{Limitations and Future Research}

Although this paper has shed light on the understanding of how work curiosity effectively affects innovative behavior to a certain extent, there still are several limitations in need of attention.

First of all, from the perspective of trait curiosity, this study explores the influence of trait work curiosity on employees' innovative behavior, and combines the four dimensions of work curiosity into one index, which confirms the positive predictive effect of curiosity on innovation. In fact, the four measurement dimensions of work curiosity include two types of epistemic curiosity and one type of interpersonal curiosity. Whether different types of curiosity can actively promote individual innovation behavior or whether different types of curiosity have different effects on different types of innovation remains to be further investigated by subsequent studies. Opportunities for future research have been inspired from a comparative study of based on different types of curiosity, ex- 
plore the relationship between different types of curiosity and innovative behavior.

Apart from that, this study uses questionnaire collection as the data source, although the design of data collection is to divide the respondents into two stages with a certain time interval to avoid common method variation, some errors may still occur. Future research could conduct standard three-stage longitudinal tracking studies to obtain samples and data from different time slots. In addition, all the variables are from employees' self-report, which may result in less objective and authentic data, which is also the weakness of this study. Similarly, future studies might through experience sampling or experimental research is used to examine more accurately the influence of arousing curiosity on employees' innovation and other work behaviors.

\section{Conflicts of Interest}

The author declares no conflicts of interest regarding the publication of this paper.

\section{References}

Aiken, L. S., West, S. G., \& Reno, R. R. (1991). Multiple Regression: Testing and Interpreting Interactions. Thousand Oaks, CA: Sage.

Amabile, T. M., Conti, R., Coon, H., Lazenby, J., \& Herron, M. (1996). Assessing the Work Environment for Creativity. Academy of Management Journal, 39, 1154-1184. https://doi.org/10.2307/256995

Amabile, T. M., Hill, K. G., Hennessey, B. A., \& Tighe, E. M. (1994). The Work Preference Inventory: Assessing Intrinsic and Extrinsic Motivational Orientations. Journal of Personality and Social Psychology, 66, 950-967. https://doi.org/10.1037/0022-3514.66.5.950

Chang, Y. Y., \& Shih, H. Y. (2019). Work Curiosity: A New Lens for Understanding Employee Creativity. Human Resource Management Review, 29, Article ID: 100672. https://doi.org/10.1016/j.hrmr.2018.10.005

Deci, E. L., \& Ryan, R. M. (1985). The General Causality Orientations Scale: Self- Determination in Personality. Journal of Research in Personality, 19, 109-134. https://doi.org/10.1016/0092-6566(85)90023-6

Fischer, C., Malycha, C. P., \& Schafmann, E. (2019). The Influence of Intrinsic Motivation and Synergistic Extrinsic Motivators on Creativity and Innovation. Frontiers in Psychology, 10, 137. https://doi.org/10.3389/fpsyg.2019.00137

Fornell, C., \& Larcker, D. F. (1981). Structural Equation Models with Unobservable Variables and Measurement Error: Algebra and Statistics. Journal of Marketing Research, 18, 382-388. https://doi.org/10.2307/3150980

Gino, F. (2018). The Business Case for Curiosity. Harvard Business Review, 96, 48-57.

Gross, M. E., Zedelius, C. M., \& Schooler, J. W. (2020). Cultivating an Understanding of Curiosity as a Seed for Creativity. Current Opinion in Behavioral Sciences, 35, 77-82. https://doi.org/10.1016/j.cobeha.2020.07.015

Hackman, J. R. (1980). Work Redesign and Motivation. Professional Psychology, 11, 445-455. https://doi.org/10.1037/0735-7028.11.3.445

Hagtvedt, L. P., Dossinger, K., Harrison, S. H., \& Huang, L. (2019). Curiosity Made the Cat More Creative: Specific Curiosity as a Driver of Creativity. Organizational Behavior 
and Human Decision Processes, 150, 1-13. https://doi.org/10.1016/j.obhdp.2018.10.007

Hardy III, J. H., Ness, A. M., \& Mecca, J. (2017). Outside the Box: Epistemic Curiosity as a Predictor of Creative Problem Solving and Creative Performance. Personality and Individual Differences, 104, 230-237. https://doi.org/10.1016/j.paid.2016.08.004

Harrison, S. H., Sluss, D. M., \& Ashforth, B. E. (2011). Curiosity Adapted the Cat: The Role of Trait Curiosity in Newcomer Adaptation. Journal of Applied Psychology, 96, 211-220. https://doi.org/10.1037/a0021647

Horstmeyer, A. (2020). The Generative Role of Curiosity in Soft Skills Development for Contemporary VUCA Environments. Journal of Organizational Change Management, 33, 737-751. https://doi.org/10.1108/JOCM-08-2019-0250

Ishaq, E., Bashir, S., Khan, A. K., Hassan, M. M., \& Zakarira, R. (2019). Epistemic Curiosity and Perceived Workload: A Moderated Mediation Model of Achievement Striving and Overwork Climate. International Journal of Human Resource Management, 1-24. https://doi.org/10.1080/09585192.2019.1641734

Karwowski, M. (2012). Did Curiosity Kill the Cat? Relationship between Trait Curiosity, Creative Self-Efficacy and Creative Personal Identity. Europe's Journal of Psychology, 8, 547-558. https://doi.org/10.5964/ejop.v8i4.513

Kashdan, T. B., Goodman, F. R., Disabato, D. J., McKnight, P. E., Kelso, K., \& Naughton, C. (2020). Curiosity Has Comprehensive Benefits in the Workplace: Developing and Validating a Multidimensional Workplace Curiosity Scale in United States and German Employees. Personality and Individual Differences, 155, Article ID: 109717. https://doi.org/10.1016/j.paid.2019.109717

Kirmeyer, S. L., \& Shirom, A. (1986). Perceived Job Autonomy in the Manufacturing Sector: Effects of Unions, Gender, and Substantive Complexity. Academy of Management Journal, 29, 832-840. https://doi.org/10.2307/255949

Lauriola, M., Litman, J. A., Mussel, P., De Santis, R., Crowson, H. M., \& Hoffman, R. R. (2015). Epistemic Curiosity and Self-Regulation. Personality and Individual Differences, 83, 202-207. https://doi.org/10.1016/j.paid.2015.04.017

Litman, J. (2005). Curiosity and the Pleasures of Learning: Wanting and Liking New Information. Cognition \& Emotion, 19, 793-814. https://doi.org/10.1080/02699930541000101

Litman, J. A. (2007). Curiosity as a Feeling of Interest and Feeling of Deprivation: The I/D Model of Curiosity. In P. R. Zelick (Ed.), Issues in the Psychology of Motivation (pp. 149-156). New York: Nova Science Publishers, Inc.

Litman, J. A. (2008). Interest and Deprivation Factors of Epistemic Curiosity. Personality and Individual Differences, 44, 1585-1595. https://doi.org/10.1016/j.paid.2008.01.014

Litman, J. A., \& Jimerson, T. L. (2004). The Measurement of Curiosity as a Feeling of Deprivation. Journal of Personality Assessment, 82, 147-157. https://doi.org/10.1207/s15327752jpa8202_3

Litman, J., Hutchins, T., \& Russon, R. (2005). Epistemic Curiosity, Feeling-of-Knowing, and Exploratory Behaviour. Cognition \& Emotion, 19, 559-582.

https://doi.org/10.1080/02699930441000427

Liu, Y., \& Shi, J. (2009). A Study on the Relationship between the Effects of the Organizational Innovative Climate and those of Motivational Preference, on Employees' Innovative Behavior. Management World, 10, 88-101+114+188.

Loewenstein, G. (1994). The Psychology of Curiosity: A Review and Reinterpretation. Psychological Bulletin, 116, 75-98. https://doi.org/10.1037/0033-2909.116.1.75

Müceldili, B., Tatar, B., \& Erdil, O. (2020). Can Curious Employees Be More Agile? The 
Role of Cognitive Style and Creative Process Engagement in Agility Performance. Global Business and Organizational Excellence, 39, 39-52.

https://doi.org/10.1002/joe.22056

Mumford, M. D., \& McIntosh, T. (2017). Creative Thinking Processes: The Past and the Future. The Journal of Creative Behavior, 51, 317-322. https://doi.org/10.1002/jocb.197

Mussel, P. (2013). Introducing the Construct Curiosity for Predicting Job Performance. Journal of Organizational Behavior, 34, 453-472. https://doi.org/10.1002/job.1809

Mussel, P., \& Spengler, M. (2015). Investigating Intellect from a Trait Activation Perspective: Identification of Situational Moderators for the Correlation with Work-Related Criteria. Journal of Research in Personality, 55, 51-60. https://doi.org/10.1016/j.jrp.2015.01.002

Podsakoff, P. M., MacKenzie, S. B., Lee, J.-Y., \& Podsakoff, N. P. (2003). Common Method Biases in Behavioral Research: A Critical Review of the Literature and Recommended Remedies. Journal of Applied Psychology, 88, 879-903. https://doi.org/10.1037/0021-9010.88.5.879

Reio, T. G., \& Callahan, J. L. (2004). Affect, Curiosity, and Socialization-Related Learning: A Path, Analysis of Antecedents to Job Performance. Journal of Business and Psychology, 19, 3-22. https://doi.org/10.1023/B:JOBU.0000040269.72795.ce

Ryan, R. M., \& Deci, E. L. (2000). Intrinsic and Extrinsic Motivations: Classic Definitions and New Directions. Contemporary Educational Psychology, 25, 54-67. https://doi.org/10.1006/ceps.1999.1020

Spector, P. E. (1986). Perceived Control by Employees: A meta-Analysis of Studies Concerning Autonomy and Participation at Work. Human Relations, 39, 1005-1016. https://doi.org/10.1177/001872678603901104

Tett, R. P., \& Burnett, D. D. (2003). A Personality Trait-Based Interactionist Model of Job Performance. Journal of Applied Psychology, 88, 500-517. https://doi.org/10.1037/0021-9010.88.3.500

Tett, R. P., \& Guterman, H. A. (2000). Situation Trait Relevance, Trait Expression, and Cross-Situational Consistency: Testing a Principle of Trait Activation. Journal of Research in Personality, 34, 397-423. https://doi.org/10.1006/jrpe.2000.2292

Tett, R. P., Simonet, D. V., Walser, B., \& Brown, C. (2013). Trait Activation Theory. In N. D. Christiansen, \& R. P. Tett (Eds.), Handbook of Personality at Work (pp. 71-100). Abingdon: Routledge.

van Knippenberg, D., \& Hirst, G. (2020). A Motivational Lens Model of Person $\times$ Situation Interactions in Employee Creativity. Journal of Applied Psychology, 105, 1129 1144. https://doi.org/10.1037/apl0000486

Wagstaff, M. F., Flores, G. L., Ahmed, R., \& Villanueva, S. (2020). Measures of Curiosity: A Literature Review. Human Resource Development Quarterly. https://doi.org/10.1002/hrdq.21417

Wang, C., \& Huang, Y. (2018). “I Want to Know the Answer! Give Me Fish'n'Chips!”: The Impact of Curiosity on Indulgent Choice. Journal of Consumer Research, 44, 1052-1067. https://doi.org/10.1093/jcr/ucx086

Wang, H., \& Li, J. (2015). How Trait Curiosity Influences Psychological Well-Being and Emotional Exhaustion: The Mediating Role of Personal Initiative. Personality and Individual Differences, 75, 135-140. https://doi.org/10.1016/j.paid.2014.11.020

Yuan, F., \& Woodman, R. W. (2010). Innovative Behavior in the Workplace: The Role of Performance and Image Outcome Expectations. Academy of Management Journal, 53, 323-342. https://doi.org/10.5465/amj.2010.49388995 